\title{
EXPERT REVIEWS \\ Primary mediastinal lymphoma: diagnosis and treatment options
}

Expert Rev. Hematol. Early online, 1-14 (2014)

Maurizio Martelli*, Alice Di Rocco, Eleonora Russo, Salvatore Perrone and Robin Foà

Hematology, Department of Cellular Biotechnologies and Hematology, University 'Sapienza', Via Benevento 6, Roma 00161, Italy

*Author for correspondence:

Tel.: + 390649974779

Fax: +39064 4241984

martelli@bce.uniroma1.it

Primary mediastinal large B-cell lymphoma $(\mathrm{PMBCL})$ is a unique $\mathrm{B}$-cell lymphoma variant that arises from a putative thymic medulla $B$ cell. It constitutes $2-4 \%$ of non-Hodgkin lymphomas and occurs most frequently in young females. $\mathrm{PMBCL}$ is characterized by a diffuse proliferation of medium-to-large B cells associated with sclerosis. Molecular analysis shows that PMBCL is a distinct entity compared to other types of diffuse large B-cell lymphomas. $\mathrm{PMBCL}$ is characterized by a locally invasive anterior mediastinal bulky mass. The combination of rituximab with $\mathrm{CHOP} / \mathrm{CHOP}$-like regimens followed by mediastinal radiation therapy (RT) is associated with a 5-year progression-free survival of $75-85 \%$. However, the role of consolidation RT still remains uncertain. More intensive regimens, such as DA-EPOCH-R without mediastinal RT, have shown very promising results. The conclusive role of PET-CT scan requires prospective studies and there is hope that this may allow to de-escalate RT and accordingly yield reliable prognostic information.

KEYwORDS: chemotherapy • histopathology $\bullet$ International Prognostic Index $\bullet$ JAK-STAT pathway $\bullet$ PET-CT scan - primary mediastinal lymphoma $\bullet$ programmed death ligand $\bullet$ radiotherapy $\bullet$ rituximab $\bullet$ third-generation regimen

Primary mediastinal large B-cell lymphoma (PMBCL) is a unique variant of $\mathrm{B}$-cell lymphoma that arises from a putative thymic medulla B cell. Because of its peculiar epidemiological, morphological and immunophenotypic characteristics, PMBCL has been identified as a specific entity recognized by the WHO classification of lymphoid malignancies $[1,2]$. PMBCL constitutes $2-4 \%$ of non-Hodgkin lymphomas (NHL) [3]. It is more common in young adults (median age 35-40 years) with a female predominance, originates in the mediastinum and is characterized by an aggressive and locally invasive behavior $[4,5]$.

\section{Diagnosis \& clinical presentation}

The diagnosis of PMBCL is based on the integration of morphological, immunophenotypic, genetic and clinical data according to the WHO classification [2]. The differential diagnosis should be primarily made with classical Hodgkin lymphoma (cHL), mediastinal gray zone lymphoma (MGZL) and other nodal diffuse large B-cell lymphoma (DLBCL)-NOS subtypes from which in some cases it cannot be readily distinguished.

\section{Histopathology \& immunophenotype}

It is postulated that PMBCL derives from the small subset of thymic B cells with asteroid shape located around the Hassall's corpuscles in the medullary thymus which share with PMBCL a CD10-, CD21-, CD23+ phenotype [6,7]. The clinical presentation within the anterior mediastinum and the identification of normal thymic cells that express the MAL protein support this hypothesis [8]. PMBCL is characterized by a diffuse proliferation of medium-to-large B cells associated with sclerosis and a degree of compartmentalization [2]. Lymphomatous elements show polymorphic nuclei and a wide rim of cytoplasm that is either clear or slightly basophilic. Less often, the neoplastic cells resemble immunoblasts. The fibrotic reaction is easily appreciated in the form of thin strands of reticulin fibers that surround clusters of neoplastic cells. In more than half of the cases, there are prominent collagen bands that emphasize the compartmentalization, which may constitute a dominant feature of the microscopic picture [9-11]. In some series, sclerosis has been defined as a diagnostic criterion, but its variability in different areas of the same tumor 
(A)
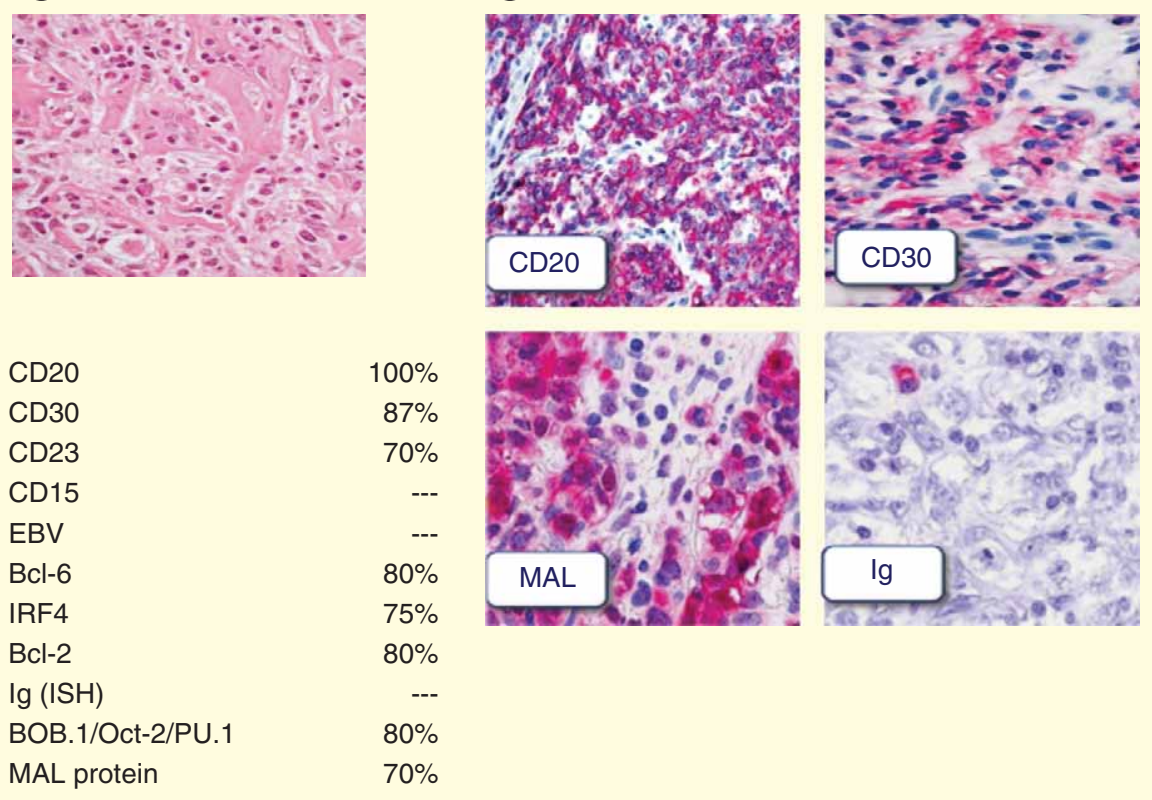

Figure 1. Histopathology and immunohistochemical findings in primary mediastinal large B-cell lymphoma. (A) Histopathology usually consists of medium to large cells with clear cytoplasm, evokes fibrosis with compartmentalization and (B) Immunohistochemistry typically shows the expression of CD30, CD20 and MAL proteins and negativity of surface and cytoplasmic immunoglobulins.

Ig: Immunoglobulin.
(B)
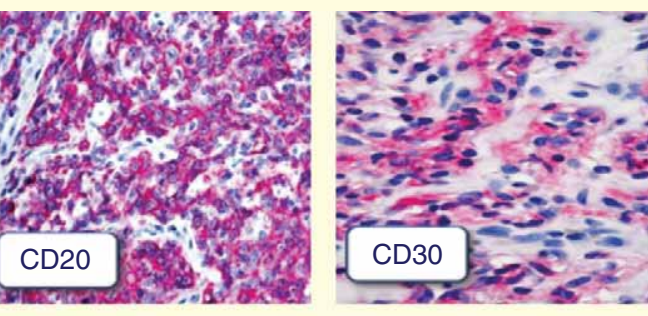

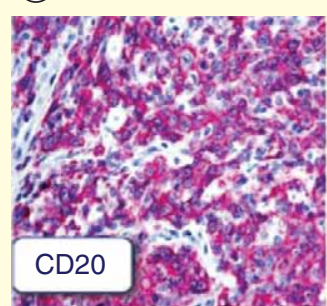

well as histiocytes in the former. In addition, cHL expresses CD15 and less often a full set of B-cell markers [19]. MAL has been reported to be specifically expressed in PMBCL but it is a rather difficult marker to stain in routine practice. Some cases with either morphological features of PMBCL but immunophenotypic features of $\mathrm{cHL}$ or vice versa do not allow a final diagnosis and are classified as B-cell lymphoma unclassifiable, with features intermediate between DLBCL and $\mathrm{cHL}$ or so-called MGZL [12]. These tumors morphologically show cells larger and more pleomorphic than in the typical cases of PMBCL. Pleomorphic cells resemble lacunar cells and Hodgkin lymphoma (HL) cells. A characteristic feature is the broad spectrum with different areas of the tumor, some more closely to cHL and others appear more like DLBCL. On immunophenotipe, analysis of neoplastic cells typically expresses CD45 but in contrast with cHL the B-cell program is often preserved but is aberrantly expressed in concert with cHL markers such as CD30 and CD15. CD20 and CD79a are also frequently positive and may be strongly expressed on the

makes this an impractical diagnostic requirement with the small biopsy samples usually available. Not infrequently, Reed-Sternberg-like cells may be seen. In such instances, careful immunohistochemical evaluation is warranted to exclude the diagnosis of cHL. In this regard, it should also be noted that 'gray zone' borderline cases combining features of PMBCL and $\mathrm{CHL}$ or cases of composite PMBCL and $\mathrm{CHL}$ can rarely be encountered [12]. Regarding immunohistochemical analysis, despite generally lacking surface and cytoplasmic immunoglobulin, PMBCL expresses B-cell-related antigens such as CD19, CD20, CD22, CD79a, PAX5 and CD45. CD30 staining is observed in the vast majority of cases $(\sim 80 \%)$ although it is weaker and less homogeneous than in cHL and anaplastic large cell lymphoma [13]. CD15 is occasionally present. Tumor cells are more frequently positive for BCL2 (55-80\%) and CD23 (70\%), while BCL6 expression is variable $(45-100 \%)$ and $\mathrm{CD} 10$ is more often negative (8$32 \%$ ) [12-15]. Tumor cells are often MAL positive as a consequence of $M A L$ gene overexpression [8,16,17]. The latter is located on the long arm of chromosome 2 and encodes a protein thought to play a role in membrane trafficking and signaling which might contribute to pathogenesis [18]. PMBCLs usually also express BOB1, PU1 and OCT2 (Figure 1) [13,14].

\section{Differential diagnostic criteria}

The main differential diagnoses are with cHL and DLBCL. cHL can be distinguished from PMBCL by histological features such as an abundant infiltration with granulocytes and lymphocytes as majority of tumor cells. The transcription factors PAX-5, OCT2 and BOB1 are also usually expressed (TABLE 1) [14,18].

The differential diagnosis with nodal DLBCL-NOS is not always easy. The distinct morphological features of PMBCL, such as clear cell proliferation and sclerosis, may be difficult to evaluate on small biopsies and there is a lack of well-defined diagnostic criteria that can be routinely applied. The expression of CD23 in PMBCL may be useful in that respect [20]. Gene expression analysis allows for an improved distinction between PMBCL and DLBCL-NOS but can as yet not be used in the clinical practice [21-23]. These difficulties are of relevant impact on evaluation of clinical trials where a mixed series of PMBCL and DLBCL-NOS might confuse the final results.

\section{Genetic characteristics}

PMBCL has a unique gene expression profile signature that is different from other nodal DLBCL and more closely related to cHL. The hallmark of the transcriptional signature of PMBCL is the deregulation of JAK-STAT signaling. The underlying genetic basis for this observation is the recurrent amplification involving $J A K 2$ on chromosome band 9p24, which occurs in $50-70 \%$ of PMBCL [24,25]. Other molecular mechanisms of JAK-STAT activation in PMBCL are the disruption of SOCS1 and PTPN1 that physiologically act as negative regulators of JAK-STAT signaling and mutations of STAT6. Multiple alterations of JAK-STAT signaling genes tend to co-occur in PMBL, suggesting an additive effect of the signaling pathway hits [26]. 
Table 1. Comparison of pathological and immunophenotypic features of primary mediastinal large B-cell lymphoma, diffuse large B-cell lymphoma, nodular sclerosis classical Hodgkin lymphoma and mediastinal gray zone lymphoma.

\begin{tabular}{|c|c|c|c|c|}
\hline Features & $\begin{array}{l}\text { Primary mediastinal } \\
\text { large B-cell } \\
\text { lymphoma }\end{array}$ & $\begin{array}{l}\text { Diffuse large B-cell } \\
\text { lymphoma }\end{array}$ & $\begin{array}{l}\text { Classical Hodgkin } \\
\text { lymphoma }\end{array}$ & $\begin{array}{l}\text { Mediastinal gray zone } \\
\text { lymphoma }\end{array}$ \\
\hline Morphology & $\begin{array}{l}\text { Sheets of large cells, } \\
\text { clear cells, } \\
\text { noninflammatory }\end{array}$ & $\begin{array}{l}\text { Sheets of large cells } \\
\text { with variable aspects }\end{array}$ & $\begin{array}{l}\text { Lacunar Hodgkin } \\
\text { Reed-Sternberg cells } \\
\text { Inflammatory } \\
\text { polymorphous infiltrate }\end{array}$ & $\begin{array}{l}\text { Sheets of pleomorphic large } \\
\text { cells, Lacunar Hodgkin Reed- } \\
\text { Stenberg cells; sparse } \\
\text { inflammatory infiltrate }\end{array}$ \\
\hline Sclerosis & $\begin{array}{l}70-100 \% \text { (alveolar, } \\
\text { fine bands) }\end{array}$ & Absent & $100 \%$ (large bands) & Focal fibrous bands \\
\hline CD45 & Positive & Positive & Negative & Positive \\
\hline CD30 & $\begin{array}{l}\text { Positive weak } \\
(70-80 \%)\end{array}$ & $\begin{array}{l}\text { Rare (anaplastic } \\
\text { variant) }\end{array}$ & Positive & Positive \\
\hline CD15 & Negative & Negative & Positive & Positive \\
\hline CD20 & Positive & Positive & Negative & Positive \\
\hline CD23 & Positive & Negative & Negative & Negative \\
\hline CD79a & Positive & Positive & Usually negative & Positive \\
\hline PAX-5 & Positive & Positive & Weak positive & Positive frequently \\
\hline Immunoglobulin & Negative & Positive & Negative & Negative \\
\hline BOB-1 & Positive & Positive & Negative & Positive frequently \\
\hline OCT-2 & Positive & Positive & Negative & Positive frequently \\
\hline MAL expression & $60-70 \%$ & $<10 \%$ & $<20 \%$ & $30-40 \%$ \\
\hline
\end{tabular}

Besides $J A K 2$, the amplified region at $9 \mathrm{p} 24$ also includes JMJD2C, CD274 (alias PDL1) and PDCD1LG2 (alias PDL2). $J A K 2$ and JMJD2C are coordinately overexpressed in PMBCL and function in concert to epigenetically modify CD274 and PDCD1LG2. Amplification and epigenetic modification function in concert to boost the expression of CD274 and PDCD1LG2, which encodes inhibitors of T-cell response essential for the malignant PMBCL clone to escape immune surveillance of the thymus microenvironment [27-29]. Translocations involving CIITA, a transactivator of MHC class II genes, occur in approximately $40 \%$ of PMBCL and represent a second mechanism of immune escape of this lymphoma. CIITA translocations invariably fuse the $\mathrm{N}$ terminus of CIITA in frame with a variety of other genes. As a result, one copy of CIITA is inactivated, and the fusion protein can also act in a dominantnegative manner to extinguish MHC class II expression, thereby limiting the ability of the tumor cells to interact with $\mathrm{T}$ cells [30]. JAK inhibitors switching off PDL expression and downmodulating the canonical JAK-STAT signaling could be considered as preclinical model for a targeted therapy of PMBCL [31,32] (Figure 2).

\section{Clinical presentation \& prognostic factors}

PMBCL normally presents with a bulky tumor in the anterior mediastinum that is rapidly progressive and gives rise to local compressive symptoms including early dyspnea, cough, dysphagia and compromising the airway or great vessels, producing a superior vena cava syndrome. Up to one-half of patients have symptoms and signs of superior vena cava syndrome, thoracic and neck vein distension, facial edema, conjunctival swelling and occasionally arm edema. This results in relatively early presentation so that at diagnosis most patients (around 80\%) have stage I or II disease. The mediastinal tumor is frequently bulky, being over $10 \mathrm{~cm}$ in about $70-80 \%$ of patients, infiltrating the lungs, chest wall, pleura and pericardium [3,33]. Pleural or pericardial effusions are present in one-third of cases [34,35]. Breast edema is common and hoarseness may reflect recurrent laryngeal nerve damage (Figure 3).

Despite the local invasiveness, distant spread is infrequent at the onset and even spread to the supraclavicular nodes is usual at presentation. Extranodal sites may however be involved, particularly in cases of disease recurrence, with a propensity for involvement of the kidneys, adrenal glands, liver, ovaries and CNS [36-38]. The duration of symptoms is rarely longer than 3 months. Systemic symptoms, mainly fever or weight loss, are present in less than $20 \%$ of cases. Spread to marrow or cerebrospinal fluid involvement is unusual. Moderate to high LDH levels are observed in $70-80 \%$ of cases [39]. MGZL shows similar clinical features, but compared to PMBCL it is more common in young men and more often presents extranodal 


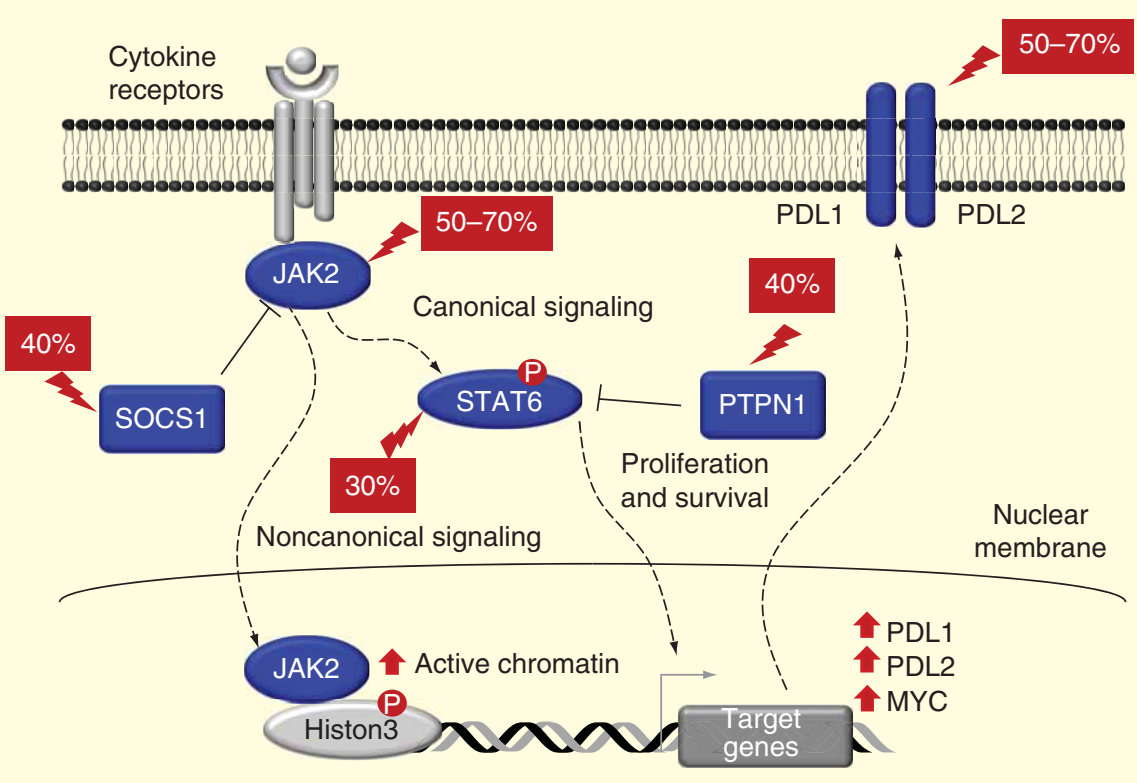

Figure 2. JAK-STAT pathway deregulation and regulation of PDL1 and PDL2 expression.

PDL: Programmed death ligand.

involvement and B symptoms. MGZL showed a significant poor prognostic outcome when compared to PMBCL (TABLE 2) [40].

The complete staging workup includes an accurate physical examination, complete hematological and biochemical examinations, total body computerized tomography (CT) and bone marrow biopsy. A diagnostic tissue sample can be obtained by mediastinoscopy, biopsy of the tumor mass through the supraclavicular fossa, anterior mediastinotomy or minithoracotomy. It

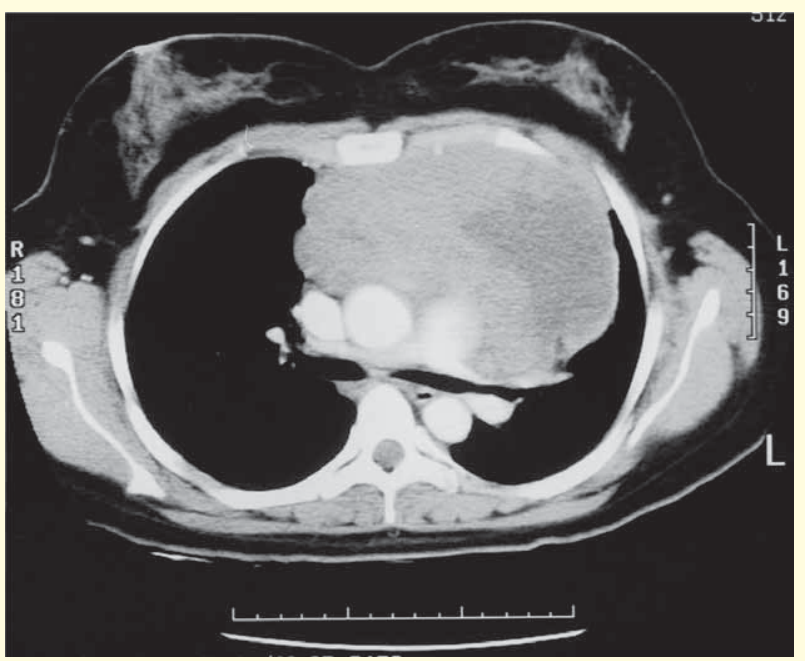

Figure 3. CT scan from a female patient presenting with primary mediastinal large B-cell lymphoma. Note the large anterior mediastinal mass, with areas suggestive of central necrosis and bilateral breast edema. is important to consider the anesthetic risk for patients with critical airways narrowing by anterior mediastinal tumors: sometimes it may be preferable to obtain a needle core biopsy by a percutaneous route under local anesthesia rather than to obtain a larger biopsy but having a patient who cannot be extubated following the procedure because of an airway compromise [41]. PMBCL shows almost universal avidity for [18F]-2-fluoro-2-deoxyglucose, making PET (FDG-PET) an effective means to assess disease extent and to characterize residual masses at the completion of treatment. The extent of experience with this technique is however too limited to permit major changes to therapy based upon FDG-PET scans, pending the results of prospective trials. The utility of the International Prognostic Index (IPI) in PMBCL is limited by the age distribution of the disease and its usual confinement to the mediastinum. This is reflected by the observation that half of the patients have low IPI scores at presentation [39]. The ageadjusted IPI has similarly been reported to be of limited predictive value in PMBCL. This may reflect differences between studies, assigning patients as either stage IV or stage IIE when contiguous extranodal sites such as the lungs are involved [42-45]. An elevated LDH to more than twice the upper limit of normal, age over 40 and performance status $\geq 2$ correlated with reduced survival in a population-based series from British Columbia [44], while in a large series from the International Extranodal Lymphoma Study Group (IELSG), male sex, poor performance status and advanced-stage disease were significant negative predictors [46]. The presence of noncontiguous mediastinal extranodal disease (kidneys, adrenal glands, liver and ovaries) at diagnosis and/or early inadequate response to induction therapy, considered as a response less than partial response (PR), should be considered as significant prognostic factors for a poor outcome [43].

\section{Treatment \& outcome}

The first-line treatment and its outcome are critical in managing PMBCL. Salvage treatment for recurrence/progression of disease is of limited efficacy. On the basis of this concept, it is imperative to cure the disease with the first-line treatment. The first issue to consider is represented by the choice of initial chemotherapy: first-generation versus third-generation chemotherapy regimens and the inclusion of rituximab in the front-line treatment. Other issues include any potential benefit from high-dose therapy (HDT) in first remission, the role of consolidation radiotherapy to the mediastinum and the potential role of functional imaging (FDG-PET) to guide treatment choices. It is however important to strike an appropriate balance between 
Table 2. Comparison of clinical features of primary mediastinal large B-cell lymphoma, diffuse large B-cell lymphoma, nodular sclerosis classical Hodgkin lymphoma and mediastinal gray zone lymphoma.

\begin{tabular}{|lllll}
\hline Features & $\begin{array}{l}\text { Primary mediastinal } \\
\text { large B-cell lymphoma }\end{array}$ & $\begin{array}{l}\text { Diffuse large } \\
\text { B-cell lymphoma }\end{array}$ & $\begin{array}{l}\text { Classical Hodgkin } \\
\text { lymphoma }\end{array}$ & $\begin{array}{l}\text { Mediastinal gray } \\
\text { zone lymphoma }\end{array}$ \\
\hline Female/male ratio & $2: 1$ & $1: 1$ & $1: 1$ & $1: 2$ \\
\hline Median age (years) & 35 & 55 & 28 & 35 \\
\hline Stage I-II & $70-80 \%$ & $30 \%$ & $55 \%$ & $70-80 \%$ \\
\hline Mediastinal involvement & All & $20 \%$ & $80 \%$ & $80 \%$ \\
\hline Extranodal sites & Uncommon & Common & Uncommon & $3 \%$ \\
\hline Bone marrow & $2 \%$ & $10-15 \%$ & $3 \%$ & $70-80 \%$ \\
\hline Elevated LDH & $70-80 \%$ & $50 \%$ & Rare & $40 \%$ \\
\hline B symptoms & $<20 \%$ & $50 \%$ & $40 \%$ & $70-80 \%$
\end{tabular}

delivery of the highest possible cure fraction and minimization of long-term morbidity for this young population of patients.

Early studies suggesting that PMBCL were unusually aggressive, with a poorer prognosis with respect to other nodal diffuse large-cell lymphomas, have been contradicted by more recent reports. There is a broad agreement that for nodal DLBCL the standard of care is the R-CHOP regimen. Prior to the introduction of rituximab, some retrospective and prospective series suggested that superior outcomes in PMBCL might be achieved with more intensive third-generation regimens. Whereas the $\mathrm{CHOP}$ regimen has been used by American investigators, several European centers have suggested that the V/MACOP-B (etoposide/methotrexate, doxorubicin, cyclophosphamide, vincristine, prednisone, and bleomycin) regimen may be superior to CHOP [34,45,47-49]. However, the debate is still open because it is difficult to compare the advantages of the different types of protocols, and it is also difficult to explain the rather different complete response (CR) and survival rates reported by different institutions using similar regimens in Phase II studies. On the basis of published Phase II data by centers that have used both first-generation chemotherapy regimens such as $\mathrm{CHOP}$ and other more aggressive third-generation ones such as V/MACOP-B, the results have clearly favored the latter. Lazzarino et al. treated 30 patients; the $\mathrm{CR}$ rate after $\mathrm{CHOP}$ was $36 \%$, whereas that after MACOP-B was $73 \%$ [35]. In an Italian multicenter study of 106 patients, the 3-year relapse-free survival (RFS) was $38 \%$ in the 47 patients treated with $\mathrm{CHOP}$, whereas it was $58 \%$ in the 62 patients treated with MACOP-B or VACOP-B [43]. In two Italian prospective studies, we used the MACOP-B regimen in 50 and 89 patients and the CR rates were 86 and $88 \%$, respectively, whereas the 5-year RFS rates were 93 and 91\%, respectively [48,49]. In addition, two retrospective studies have reported data regarding the comparison between $\mathrm{CHOP}$ and $\mathrm{CHOP}-$ like regimens versus MACOP-B and MACOP-B-like regimens as induction chemotherapy in patients with PMBCL. In the first study,
Todeschini et al. reported the long-term results from a retrospective multicenter Italian experience in 138 patients with PMBCL treated with CHOP (43 patients) or MACOP$\mathrm{B} / \mathrm{VACOP}-\mathrm{B}$ (95 patients). The CR rate was $51 \%$ in the CHOP group and $80 \%$ in the MACOP-B/VACOP-B group. The addition of radiation therapy (RT) on mediastinum mass consolidation improved the outcome regardless of the type of chemotherapy [45]. In a multinational retrospective study from the IELSG, which reviewed the outcomes of 426 previously untreated patients with PMBCL after first-generation (CHOP and CHOP-like regimens; 105 patients), third-generation (MACOP-B, VACOP-B; 277 patients) and high-dose chemotherapy schedules (high-dose sequential and autologous stem cells transplantation; 44 patients). In all these groups, the majority of patients underwent RT after chemotherapy. Although the CR rate was similar between the third-generation subgroup and those treated with conventional $\mathrm{CHOP} / \mathrm{CHOP}$ like regimens, the relapse rate at 3 years was significantly lower in the third-generation group ( 12 vs $23 \%$; $\mathrm{p}=0.02)$ and the projected 10 years overall survival (OS) and PFS were superior at 71 and $67 \%$ compared to 44 and $33 \%$ ( $p=0.0001$ and $\mathrm{p}=0.0003)$, respectively) [46]. These two retrospective studies suggest the superiority of the third-generation chemotherapy strategies over the first-generation ones. In addition, they highlight the role of RT for converting from PR to CR, and probably also of consolidating the CR (TABLE 3). However, the following introduction of rituximab in the clinical practice guidelines has changed this opinion. The British Columbia Cancer Agency (BCCA) carried out a population-based retrospective analysis of 153 patients with PMBCL whose treatment was determined by era-specific guidelines. The 5 -year OS for the entire cohort was $75 \%$, with a 5 -year OS of $87 \%$ for those treated with MACOP-B/VACOP-B, which is significantly higher than the $71 \%$ for patients treated with $\mathrm{CHOP}$ $(\mathrm{p}=0.048)$. In the multivariate analysis for OS, the type of chemotherapy regimen showed a trend toward improved 
Table 3. Reported studies on management and outcome of patients with primary mediastinal large B-cell lymphoma treated in the pre-rituximab era.

\begin{tabular}{|c|c|c|c|c|c|c|}
\hline Study (year) & Patients (N) & Regimen & CR rate $(\%)$ & RFS (\%) & OS $(\%)$ & Ref. \\
\hline Todeschini et al. (1990) & 21 & $\begin{array}{l}\text { CHOP (6) } \\
\text { MACOP-B (15) }\end{array}$ & $\begin{array}{l}0 \\
87\end{array}$ & 90 (5 years) & $\mathrm{nr}$ & {$[50]$} \\
\hline Lazzarino et al. (1993) & 30 & $\begin{array}{l}\text { CHOP } \\
\text { MACOP-B }\end{array}$ & $\begin{array}{l}36 \\
73\end{array}$ & 72 (3 years) & 36 (3 years) & [35] \\
\hline $\begin{array}{l}\text { Cazals-Hatem et al. } \\
\text { (1996) }\end{array}$ & 141 & $\begin{array}{l}\text { M-BACOD } \\
\text { ACVBP }\end{array}$ & 79 & 61 (3 years) & 66 (3 years) & {$[4]$} \\
\hline Lazzarino et al. (1997) & 106 & $\begin{array}{l}\text { CHOP (47) } \\
\text { V/MACOP-B (62) }\end{array}$ & $\begin{array}{l}37 \\
58\end{array}$ & 71 (3 years) & 52 (3 years) & {$[43]$} \\
\hline Martelli et al. (1998) & 37 & $\begin{array}{l}\text { MACOP-B + IFRT (27) } \\
\text { F-MACHOP + IFRT (10) }\end{array}$ & $\begin{array}{l}88 \\
60\end{array}$ & $\begin{array}{l}91 \text { ( } 5 \text { years } \\
60 \text { ( } 5 \text { years) }\end{array}$ & $\begin{array}{l}93 \text { (5 years) } \\
70 \text { (5 years) }\end{array}$ & {$[47]$} \\
\hline Zinzani et al. (1999) & 50 & MACOP-B + IFRT & 86 & 93 (5 years) & 73 (3 years) & [49] \\
\hline Zinzani et al. (2001) & 89 & MACOP-B + IFRT & 88 & 91 (5 years) & 34 (3 years) & [48] \\
\hline Todeschini et al. (2004) & 138 & $\begin{array}{l}\mathrm{CHOP} \pm \mathrm{IFRT}(43) \\
\mathrm{V} / \mathrm{MACOP}-\mathrm{B} \pm \text { IFRT (95) }\end{array}$ & $\begin{array}{l}51 \\
80\end{array}$ & $\begin{array}{l}39 \text { (5 years) } \\
76 \text { (5 years) }\end{array}$ & $\begin{array}{l}\mathrm{nr} \\
\mathrm{nr}\end{array}$ & {$[45]$} \\
\hline Zinzani et al. (2002) & 426 & $\begin{array}{l}\text { CHOP } \pm \text { IFRT }(105) \\
\text { V/MACOP-B } \pm \text { IFRT (277) } \\
\text { HDS-ASCT (44) }\end{array}$ & $\begin{array}{l}61 \\
79 \\
75\end{array}$ & $\begin{array}{l}33 \text { (10 years) } \\
67 \text { (10 years) } \\
78 \text { (10 years) }\end{array}$ & $\begin{array}{l}44 \text { (10 years) } \\
71 \text { (10 years) } \\
77 \text { (10 years) }\end{array}$ & [46] \\
\hline De Sanctis et al. (2006) & 92 & MACOP-B + IFRT & 87 & 81 (5 years) & 82 (5 years) & [58] \\
\hline Mazzarotto et al. (2007) & 53 & V/MACOP-B + IFRT & 42 & 87 (5 years) & 94 (5 years) & {$[57]$} \\
\hline
\end{tabular}

outcomes but this was not statistically significant. However, in patients receiving R-CHOP this difference disappeared [44]. It is generally accepted that the addition of rituximab to chemotherapy for PMBCL yields superior results. The MabThera International Trial (MiNT) compared the outcomes for 824 patients with low-risk DLBCL randomized to receive CHOP-like chemotherapy with or without rituximab, which included a subset of 87 patients with low IPI risk PMBCL. The difference in OS did not reach statistical significance owing to the small number of PMBCL (3-year OS 78 vs $89 \%$; $p=0.16)$, but was of the same order as that seen for the whole trial (85 vs 93\%; p < 0.001) [50]. In a small series from Israel, the addition of rituximab appeared to improve PFS, particularly in patients receiving $\mathrm{CHOP}$, while there was no difference in outcome in a comparison between either a third-generation regimen with rituximab (R-M/VACOP-B) or R-CHOP (84 and 74\%, respectively; $\mathrm{p}=0.44$ ) [51]. On the other hand, in a recent study including all IPI risk patients with PMBCL treated with conventional R-CHOP showed an unacceptably high rate of primary refractory disease in $13 / 63(21 \%)$ with a 5 -year PFS and OS of 68 and 79\%, respectively. In particular patients with a high IPI score and advanced extranodal disease had a significantly worse outcome [52]. In an Italian retrospective analysis, 45 previously untreated patients with PMBCL were treated with a combination of a third-generation chemotherapy regimen V/MACOP-B concurrent with rituximab and mediastinal RT. The projected 5-year OS and RFS were 80 and $88 \%$, respectively. In comparison with historical data of V/MACOP-B without rituximab, we did not find any significant difference [53]. Overall, it appears likely that the use of rituximab reduces the distinction between different chemotherapy regimens and R-CHOP should be considered the most widely used regimen in PMBCL [54]. However, unlike for other types of DLBCL in PMBCL, the more intensive weekly regimens (V/MACOP-B) or a dose-dense CHOP (CHOP-14) combined with rituximab could improve the quality of clinical response and PFS over the standard R-CHOP-21. This could be explained by the more similar biology of PMBCL to HL in which the increase of dose intensity (BEACOPP/esc) has improved both OS and PFS. More recently in a single group Phase II study from the National Cancer Institute, the addition of rituximab to infusional dose-adjusted etoposide, doxorubicin and cyclophosphamide with vincristine, prednisone (DAEPOCH-R) without radiotherapy in 51 patients with untreated PMBCL has shown a very favorable outcome with CR in 48/ $51(94 \%)$ and a 3-year event-free survival (EFS) and OS of 93 and 97\%, respectively. Only three patients had evidence of disease after DA-EPOCH-R treatment; two had persistent focal disease, as detected on FDG-PET-CT and one had disease progression. Two of these patients underwent mediastinal consolidation radiotherapy and one was observed after excisional biopsy. These results were also confirmed in a retrospective 
Table 4. Reported studies on management and outcome of patients with primary mediastinal large B-cell lymphoma treated in the post-rituximab era.

\begin{tabular}{|c|c|c|c|c|c|c|}
\hline Study (year) & Patients (N) & Regimen & CR rate $(\%)$ & $\operatorname{RFS}(\%)$ & $\operatorname{OS}(\%)$ & Ref. \\
\hline Savage et al. (2006) & 153 & $\begin{array}{l}\text { MACOP-B (47) } \\
\text { CHOP (67) } \\
\text { R-CHOP (19) }\end{array}$ & $77^{\dagger}$ & $69(5 \text { years })^{\dagger}$ & $\begin{array}{l}87 \text { (5 years) } \\
71 \text { (5 years) } \\
81 \text { (5 years) }\end{array}$ & [44] \\
\hline Zinzani et al. (2009) & 45 & R-V/MACOP-B + IFRT & 62 & 88 (5 years) & 80 (5 years) & [54] \\
\hline Moskowitz et al. (2010) & 54 & R-CHOP14-ICE & 82 & 78 (3 years) & 88 (3 years) & [65] \\
\hline Rieger et al. (2010) & 87 & $\begin{array}{l}\text { CHOP-like (43) } \\
\text { R-CHOP-like (44) }\end{array}$ & $\begin{array}{l}54 \\
80\end{array}$ & $\begin{array}{l}64 \text { (3 years) } \\
88 \text { (3 years) }\end{array}$ & $\begin{array}{l}78 \text { (3 years) } \\
88 \text { (35 years) }\end{array}$ & [51] \\
\hline Vassilakopoulos et al. (2012) & 120 & $\begin{array}{l}\text { R-CHOP (75) } \\
\text { CHOP (45) }\end{array}$ & $\begin{array}{l}90 \\
64\end{array}$ & $\begin{array}{l}81 \text { (5 years) } \\
48 \text { (5 years) }\end{array}$ & $\begin{array}{l}91 \text { (5 years) } \\
69 \text { (5 years) }\end{array}$ & [55] \\
\hline Dunleavy et al. (2013) & 51 & DA-EPOCH-R & 94 & 93 (3 years) & 97 (3 years) & [56] \\
\hline Avigdor et al. (2014) & 95 & $\begin{array}{l}\text { R-VACOP-B/R-CHOP (43) } \\
\text { VACOP/B- CHOP(52) }\end{array}$ & 82 & $\begin{array}{l}79 \text { (5 years) } \\
58 \text { (5 years) }\end{array}$ & $\begin{array}{l}97 \text { (5 years) } \\
88 \text { (5 years) }\end{array}$ & [52] \\
\hline Soumerai et al. (2014) & 63 & $\mathrm{R}-\mathrm{CHOP}$ & 71 & 68 (5 years) & 79 (5 years) & [53] \\
\hline
\end{tabular}

Stanford cohort where 16 patients with PMBCL treated with DA-EPOCH-R were $100 \%$ alive and event-free over a median follow-up of 37 months [55]. However, these enthusiastic results represent a series of patients accrued over more than a decade at a single institution, and for these reasons need to be validated in larger multicenter trials (TABLE 4).

\section{Mediastinal consolidation radiotherapy}

Irradiation of the mediastinum is one of the most controversial aspects of the management of PMBCL. It is not attractive to administer radiation extensively to a group dominated by younger subjects, who may be put at increased risk of second malignancies, especially breast cancer and accelerated coronary artery disease. On the other hand, the chances of cure following recurrence of PMBCL are relatively poor, so that any approach which puts patients at increased risk of relapse should be strenuously avoided. It is clear from the IELSG series that many patients completing chemotherapy in PR may be converted to CR following radiotherapy [46] and that radiotherapy may render inactive residual mediastinal masses ${ }^{67}$ gallium or PET-CT positive [49] resulting in a long-term remission. Mazzarotto et al. reported that following induction chemotherapy $42 \%$ of patients were in $\mathrm{CR}$, rising to $95 \%$ following radiotherapy [56]. Univariate and multivariate analyses in two retrospective series have suggested that the use of radiotherapy was correlated with better EFS and OS $[45,46,56,57]$. Those who would prefer to avoid irradiation of the mediastinum can however point to good results in studies that have used chemotherapy alone [4]. In a BCCA retrospective study, the introduction of routine radiotherapy to consolidate response after chemoimmunotherapy was not accompanied by any improvement in PFS and OS, even for initially bulky disease [44]. The study from Memorial Sloan-Kettering Cancer Center (MSKCC) which used radiotherapy in only $7 \%$ of patients treated with the NHL-15 regimen showed excellent results, with an OS of $84 \%$ at a median follow-up of over 10 years [42]. Similarly, the excellent results that have been recently reported with DA-EPOCH-R have further strenghtened this argument, with 93\% of EFS among 51 patients. Only two of them received radiotherapy, purporting to negate the need for radiation in this disease [55]. Given the concerns about the long-term toxicity of radiation, a randomized study is needed to address its role, especially now that rituximab is incorporated into the treatment of PMBCL. For this reason, an international Phase III randomized trial (IELSG 37) is now ongoing to assess the role of consolidation RT in PMBCL patients with PET-negative mediastinal masses after standard chemoimmunotherapy. The trial should be able to demonstrate a noninferior outcome in patients not receiving consolidation RT [58]. The study may eventually allow to individualize treatment for each patient by adapting it to the PET response limiting the indication for additional radiotherapy only to PET-positive patients with an inadequate response to chemoimmunotherapy.

\section{Role of PET scan in assessment of response $\&$ to guide therapy choice}

The presence of bulky masses at the time of diagnosis, together with the extensive fibrotic elements of PMBCL, often results in a residual mediastinal mass being present at the completion of initial chemoimmunotherapy. It may be difficult to distinguish inert fibrous tissue from viable residual lymphoma on conventional cross-sectional imaging, and for this reason functional imaging has been extensively investigated. Functional imaging studies using PET-CT scans have suggested that it may be possible to distinguish residual mediastinal masses which contain active lymphoma from those in which only sclerotic material remains. PET-CT scans are now widely used as prognostic 


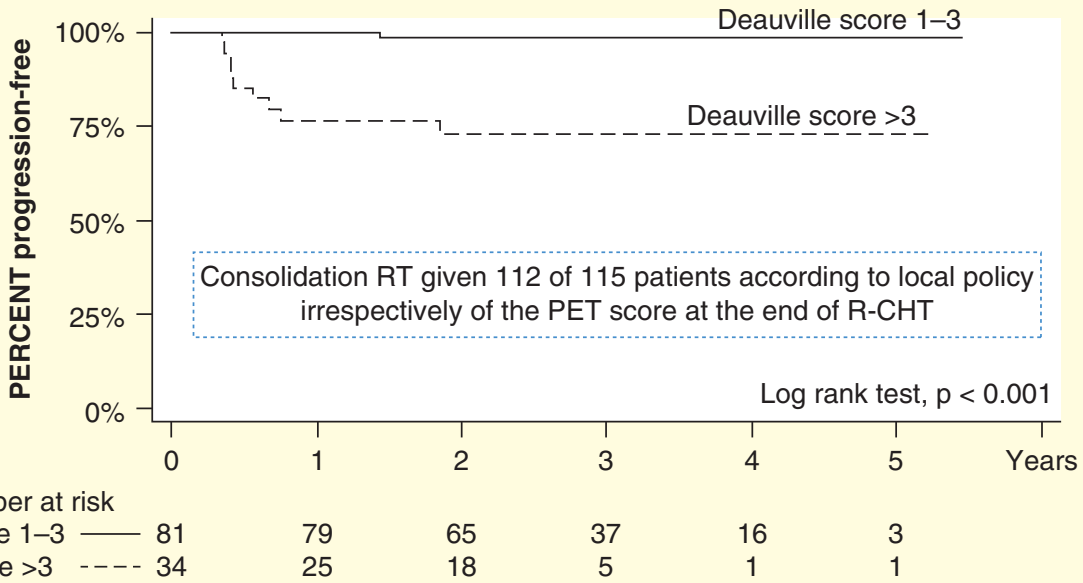

Figure 4. Progression-free survival curve in primary mediastinal large B-cell lymphoma according to PET response defined at 3-4 weeks after chemoimmunotherapy using liver uptake as a cut-off point (Deauville score 4-5) in the IELSG 26 study. Median follow-up time was 2.9 years (95\% Cl: $2.7-3.2)$. consolidation radiotherapy [65]. Similar results have been reported in two retrospective Italian trials of PMBCL [66]. In particular, the Zinzani et al. study in which a series of 74 PMBCL patients were treated with R-MACOP-B, 51 patients $(61 \%)$ who were PET positive received mediastinal RT, while the remaining 23 (39\%) who were PET negative did not. No significant differences in 5-year EFS (91 vs 90\%) were found between PET-negative and PET-positive cases [67]. The study from the National Cancer Institute using DA-EPOCH-R has further strengthened this argument, with 93\% EFS among 51 patients, only two of whom received radiotherapy [55]. Nevertheless, only a prospective randomized trial such as the ongoing IELSG 37 trial will be able to confirm or refute this. To indicators [59-61] and are incorporated in the definitions of the response criteria for DLBCL [62,63]. However, the studies performed to date in PMBCL have not yet fully clarified the role of PET-CT scans in the definition of complete metabolic response (CMR) and whether consolidation radiotherapy might be avoided solely on the basis of a negative PET-CT scan. In a retrospective study of 54 PMBCL patients treated with the R-CHOP/ICE dose-dense regimen without mediastinal RT, the MSKCC group reported 3-year OS and PFS of 88 and 78\%, respectively, in patients who were PET negative at the end of the chemotherapy regimen. An interim PET-CT scan was performed on 51/54 patients, and in 24/51 (47\%) of those patients it was abnormal but did not predict for PFS [64]. In the BCCA study, 96 PMBCL were treated with R-CHOP. Before 2005, consolidation RT to the mediastinum was routinely administered following R-CHOP, while after 2005 a PET-CT scan was planned at the end of chemotherapy to guide RT; if the PET was negative, patients were observed and if the PET was positive, consolidation RT was given if possible. Of 59 PET scans at the end of treatment, 35 (59\%) were negative (two received RT) and $24(41 \%)$ were positive (23 received RT). The recurrence rate among PET-negative patients after R-CHOP managed without RT was $6 / 35$ (four mediastinal) compared to 4/24 (three mediastinal) treated with RT. With a median follow-up of more than 5 years, there was no survival difference between PETnegative and PET-positive cases, suggesting that at least a small proportion of PET-negative patients may benefit from consolidation radiotherapy and that a PET-guided RT approach in R-CHOP-treated PMBCL may reduce the use of RT while maintaining good outcomes. However, we are also taking in account that a proportion of patients who were PET negative and did not receive RT (4/35) relapsed in the mediastinum [65]. This retrospective study from BCCA also confirmed the higher post-treatment PET-positive rate $(41 \%)$ in PMBCL than in other DLBCL, despite good clinical outcomes following assess the role of PET-CT after chemoimmunotherapy in patients with PMBCL, the IELSG started in 2007 a prospective Phase II study (IELSG 26 study). Among 125 patients prospectively enrolled, 115 were eligible for central review of PET-CT scans at the completion of standard chemoimmunotherapy using the Deauville 5-point score; $102(89 \%)$ of these patients also received a consolidation RT. Fifty-four patients (47\%) achieved a CMR, defined as a completely negative scan or with residual 18-FDG activity below the mediastinal blood pool (MBP) uptake (score 1-2). In the remaining 61 patients (53\%), the residual uptake was higher than the MBP but below the liver uptake (score 3) in 27 (23\%) and slightly and markedly higher than the liver uptake (score 4-5) in 34 (30\%). CMR after chemoimmunotherapy predicted a higher 5-year PFS (98 vs $82 \%$; $\mathrm{p}=0.0044)$ and $\mathrm{OS}(100$ vs $91 \% ; \mathrm{p}=0.0298)$. Patients with residual uptake higher than the MBP but below the liver uptake (score 3) had equally good outcomes, without any recurrence. Using the liver uptake as cut-off for PET positivity (score 4-5) discriminated most effectively between high or low risk of failure, with 5-year PFS of 99 versus 68\% (p < 0.0001) and 5-year OS of 100 versus $83 \%(p=0.0003$ ) (Figure 4). However, 90\% of patients were projected to be alive and PFS at 5 years, despite the low CMR rate (47\%) and a very low positive-predict value of $18 \%$ after chemoimmunotherapy albeit after the use of consolidation radiotherapy in 102 cases [68]. Similarly, the series of patients treated with the DA-EPOCH-R regimen showed a $50 \%$ PET positivity, defined by FDG uptake greater than the $\mathrm{MBP}$ at the completion of chemoimmunotherapy, but only $3 / 18$ had progressive disease without the use of consolidation radiotherapy. All cases that recurred had a standardized uptake value of at least 5, and the authors therefore suggested that radiotherapy might reasonably be omitted for nearly all patients treated with this regimen [55]. In the IELSG 26 study, we have also measured, in 103 of 125 patients, the standardized uptake value, metabolic tumor volume and total lesions glycolysis 
(TLG) at the baseline PET-CT scans according to the standard protocol. At 5 years, the OS was $100 \%$ for patients with low TLG compared to $80 \%$ for those with high TLG ( $\mathrm{p}=0.0001)$, while the PFS was 97 versus 64\%, respectively $(\mathrm{p}<0.0001)$. The value of TLG on baseline PET scan outcome should be considered in future studies as a powerful predictor in PMBCL [69].

These data indicate that PET-CT scan in PMBCL has an excellent negative predictive value but limited positive predictive value due to high frequency of positive scans. This false positive rate in particular requires further definition before modifying planned therapy based upon FDG-PET evaluation alone in PMBCL, although deescalation of therapy based upon the finding of a negative FDG-PET scan is entering clinical practice. Several patients with persistent metabolically active masses underwent biopsies, which showed necrosis but no lymphoma. It has been suggested that an inflammatory response produced by the addition of rituximab to chemotherapy or a thymic rebound, which is particularly relevant given the location of the disease and their generally young age, may cause increased FDG uptake and thus reduce the positivepredict value and specificity [70]. A longer interval might result in a lower rate of false positive scans, but at the potential risk of missing the opportunity for a curative RT in some patients with persistent disease (Figure 5).

\section{High-dose therapy \& ASCT as intensification of first remission}

The low frequency of marrow involvement and the relatively young age of the PMBCL patient population are the basis for consideration of HDT and peripheral blood progenitor rescue to consolidate first remission. In the GELTAMO series, 35 patients in first CR, but considered at 'high risk' of relapse, underwent HDT with various preparative regimens. At 4 years, the OS and PFS were 84 and $81 \%$, respectively [71]. In the Memorial Sloan-Kettering experience, HDT with progenitor cell rescue at first remission was not superior to dose-dense sequential therapy [42]. Based upon the results achieved with third-generation regimens and the likely benefit from the addition of rituximab, there is no good evidence to recommend a HDT to consolidate first $\mathrm{CR}$, even in poorrisk patients. The results obtained with $\mathrm{R}-\mathrm{CHOP} / \mathrm{MACOP}-\mathrm{B}$ with/without mediastinal RT or with a more intensive chemoimmunotherapy regimen such as DA-EPOCH-R appear comparable with the reports of HDT-ASCT as consolidation first-line therapy. The exception to this may be for those

Figure 5. Basal and post-chemoimmunotherapy PET-CT scan of two young female patients with primary mediastinal large B-cell lymphoma treated with (R-MACOP-B). (A) At the completion of chemoimmunothercompletion of chemoimmunotherapy, the patient presented a score of 4 according to the Deauville 5-point score.

phose lymphoma progress or obtain an inadequate response during first-line therapy and with a positive post chemoimmunotherapy PET-CT scan. However, these groups of patients have a very poor outlook and it is appropriate in this setting to test chemosensitivity to a second-line regimen prior to myeloablative treatment and consolidate the response with involved field RT.

\section{Treatment of recurrent disease}

The probability of recurrence after successful initial therapy for PMBCL appears to be lower than that of DLBCL in general, although this may reflect the earlier stage at presentation, the younger age or possibly the biology of the disease. Patients with PMBCL who achieve a response lasting longer than 18 months after diagnosis are likely to be cured. Treatment failure usually occurs either during initial treatment or within the first 6 to 12 months after completion of treatment $[37,43,49]$. Most patients with PMBCL will initially respond to therapy with a rapid decrease in the tumor mass, but rapid disease progression during treatment cycles is not uncommon. PMBCL can either recur locally in the mediastinum or can spread to parenchymal organs, especially the kidneys and spleen. Bone marrow and CNS involvement are rare even at the time of recurrence [36]. Second-line treatment strategies are similar to those used for DLBCL, attempting reinduction with non-crossresistant agents, followed by consolidation with HDT-ASCT in those with a chemosensitive disease. In general, the outcomes of these patients have been disappointing [72,73]. The broad use of rituximab in first-line therapy has made recurrence less frequent but harder to manage successfully [74]. 


\section{Novel approaches \& biological agents}

JAK-STAT pathway deregulation is the hallmark of PMBCL and $\mathrm{CHL}$ and positively regulates the expression of PDL1 and PDL2. PDL1 and PDL2 overexpression are instrumental in PMBCL to survive in the thymic microenvironment. JAK inhibitors switch off PDL expression and downmodulate the canonical JAK-STAT signaling [28-30]. The results of these studies have shed light on the biology of PMBCL, and some of the dysregulated molecular mechanisms described above will become a preclinical model for a future targeted therapy. Preclinical studies show that selective inhibition of JAK2 with fedratinib reduces phosphorylation of JAK2 and other proteins from the STAT family in cHL and PMBCL cell lines. It also inhibits the expression of PDL1. In murine models, the inhibition of JAK2 decreased significantly tumor growth and prolonged survival, which was correlated with reduced STAT3 expression [31]. PDL1 has already become a target in clinical trials in different cancers with response rates in the range of $20-25 \%$ and it seems to be also a natural targeted therapy for lymphomas overexpressing PDL [75]. Several agents targeting the PD-1 pathway have been studied in hematological malignancies. In particular, pidilizumab (humanized IgG-1 recombinant monoclonal antibody) and nivolumab (fully humanized IgG-4 monoclonal antibody) directed at the PD-1 receptor have shown a significant activity in Phase I-Ib trials for relapsed/refractory non-Hodgkin lymphoma [76]. A Phase II trial is currently registered on clinicaltrials.gov for nivolumab in patients with relapsed/refractory DLBCL/PMBCL who failed ASCT or two prior standard regimens and are transplant ineligible [77].

\section{Expert commentary}

PMBCL is a distinct clinical and biological entity characterized by aggressive and locally invasive behavior that can lead to a respiratory clinical emergency. We recommend an accurate histological diagnosis to exclude other mediastinal lymphomas (cHL, MGZL) followed by a rapid start of chemotherapy. The combination of rituximab with $\mathrm{CHOP} / \mathrm{CHOP}$-like (R-CHOP) or with V/MACOP-B or dose-dense CHOP (CHOP14) regimens should be considered as the current standard treatment. The role of rituximab combined with more intensive chemotherapy regimens (DA-EPOCH-R) needs to be further confirmed on a larger series of patients. A post-treatment PET-CT response evaluation should be performed not before 5-6 weeks from the last infusion of chemotherapy to minimize the incidence of false positive scans. Patients with residual and metabolically active masses should be considered as partial responders and treated with mediastinal RT. Patients with a negative post chemotherapy PET-CT scan should be considered as metabolic CR. In this group of patients, the role of consolidative RT is still a matter of debate. The results of the ongoing comparative randomized trial will allow to assess if a consolidative RT could be spared in patients with a negative PET-CT scan. Considering the results achieved with conventional rituximab combination regimens or with more intensive regimens such as DA-EPOCH-R, there is no good evidence to recommend a HDT-ASCT to consolidate first CR, even in poor-risk patients. An intensification therapy with HDT-ASCT should be reserved only for patients who obtain an inadequate response with an elevated FDG uptake at the post chemoimmunotherapy PET-CT scan. Salvage treatment strategies of relapsed/resistant patients are similar to those utilized for DLBCL, attempting reinductions with non-cross-resistant agents, followed by consolidation with HDT-ASCT in patients with chemosensitive disease.

\section{Five-year view}

In the next 5 years, we could hope to solve the following clinical open questions in the management of PMBCL: Conclusively define the efficacy and safety of more intensive chemotherapy regimens, such as DA-EPOCH-R, in a larger multicenter series of patients. Clarify if consolidative mediastinal RT could be spared in selected patients and if PET-CT scans can drive this selection. An international Phase III randomized trial (IELSG 37) is now ongoing to assess the role of consolidation RT in patients with post chemoimmunotherapy PET-negative mediastinal masses. Evaluate the role and impact of new biological drugs targeting selective pathways (JAKSTAT, PDL1, PDL2).

\section{Acknowledgements}

The authors are grateful to S Pileri and D Rossi for scientific contributions and O Bagni (Nuclear Medicine Latina) for the clinical and diagnostic PET-CT support.

\section{Financial \& competing interests disclosure}

This work was endorsed by the Italian Lymphoma Foundation. M Martelli reports grants and personal fees from Roche, Mundipharma and Celgene. $R$ Foà reports grants and personal fees from Roche, Genentech, Janssen, Gilead, Amgen and Celgene. The authors have no other relevant affiliations or financial involvement with any organization or entity with a financial interest in or financial conflict with the subject matter or materials discussed in the manuscript apart from those disclosed.

No writing assistance was utilized in the production of this manuscript. 


\section{Key issues}

- Primary mediastinal large B-cell lymphoma (PMBCL) is a distinct clinical and biological entity from other types of diffuse large B-cell lymphoma (DLBCL).

- PMBCL has a better outcome compared to other nodal DLBCL probably related to younger age and localized disease.

- Rituximab combination with CHOP/CHOP-like regimens could nullify the differences with more intensive third-generation regimens (e.g., V/MACOP-B).

- R-CHOP/CHOP-like and MACOP-BNACOP-B therapies with consolidation mediastinal RT in selected patients should be considered as the standard treatment.

- DA-EPOCH-R without mediastinal radiation therapy has shown very promising results, but this therapeutic advance needs to be confirmed in further prospective trials.

- The rate of post treatment PET positivity is higher than in other $\mathrm{DLBCL}$, using the mediastinal blood pool cut-point; however, posttreatment negative PET-computerized tomography is significantly associated with a better survival.

- The liver uptake according to Deauville visual analysis may represent a more appropriate cut-point to identify patients with increased risk of relapse.

- The real role of consolidative mediastinal radiotherapy needs to be better assessed in prospective comparative studies.

- Recent investigations have brought new insight into the molecular mechanisms that contribute to the malignant phenotype of PMBCL and this may lead to a future development of targeted therapies.

\section{References}

Papers of special note have been highlighted as:

- of interest

-• of considerable interest

1. Harris NL, Jaffe ES, Diebold J, et al. World Health Organization classification of neoplastic diseases of the hematopoietic and lymphoid tissues: report of the clinical advisory Committee Meeting - Airlie House, Virginia, November 1997. J Clin Oncol 1999;17(12):3835-49

2. Swerdlow SH, Campo E, Harris NL, et al. WHO classification of tumours of haematopoietic and lymphoid tissues. International Agency for Research on Cancer; Lyon, France: 2008

3. Levitt LJ, Aisenberg AC, Harris NL, et al. Primary Non-Hodgkin's lymphoma of the mediastinum. Cancer 1982;50(11): 2486-92

4. Cazals-Hatem D, Lepage E, Brice P, et al. Primary mediastinal large B-cell lymphoma. A clinicopathologic study of 141 cases compared with 916 nonmediastinal large B-cell lymphomas, a GELA (Groupe d'Etude des Lymphomes de l'Adulte) study. Am J Surg Pathol 1996;20(7):877-88

5. Armitage JO, Weisenburger DD. New approach to classifying non-Hodgkin's lymphomas: clinical features of the major histologic subtypes. Non-Hodgkin's Lymphoma Classification Project. J Clin Oncol 1998;16(8):2780-95

6. Addis BJ, Isaacson PG. Large cell lymphoma of the mediastinum: a B-cell tumour of probable thymic origin. Histopathology 1986;10(4):379-90

7. Hofmann WJ, Momburg F, Moller P, Otto HF. Intra- and extrathymic B cells in physiologic and pathologic conditions. Immunohistochemical study on normal thymus and lymphofollicular hyperplasia of the thymus. Virchows Arch A Pathol Anat Histopathol 1988;412(5):431-42

8. Copie-Bergman C, Gaulard P, Maouche-Chretien L, et al. The MAL gene is expressed in primary mediastinal large B-cell lymphoma. Blood 1999;94(10): 3567-75

9. Möller P, Lämmler B, Eberlein-Gonska M, et al. Primary mediastinal clear cell lymphoma. Virchows Archiv A 1986; 409(1):79-92

10. Paulli M, Strater J, Gianelli U, et al. Mediastinal B-cell lymphoma: a study of its histomorphologic spectrum based on 109 cases. Hum Pathol 1999;30(2):178-87

11. Barth TF, Leithauser F, Joos $S$, et al. Mediastinal (thymic) large B-cell lymphoma: where do we stand? Lancet Oncol 2002;3(4):229-34

12. Traverse-Glehen A, Pittaluga S, Gaulard P, et al. Mediastinal gray zone lymphoma: the missing link between classic Hodgkin's lymphoma and mediastinal large B-cell lymphoma. Am J Surg Pathol 2005;29(11): 1411-21

13. Pileri SA, Gaidano G, Zinzani PL, et al. Primary mediastinal B-cell lymphoma: high frequency of BCL-6 mutations and consistent expression of the transcription factors OCT-2, BOB.1, and PU.1 in the absence of immunoglobulins. Am J Pathol 2003;162(1):243-53

14. Loddenkemper C, Anagnostopoulos I, Hummel M, et al. Differential Emu enhancer activity and expression of BOB.1/ OBF.1, Oct2, PU.1, and immunoglobulin in reactive B-cell populations, B-cell non-Hodgkin lymphomas, and Hodgkin lymphomas. J Pathol 2004;202(1): 60-9

15. de Leval L, Ferry JA, Falini B, et al. Expression of bcl- 6 and CD10 in primary mediastinal large B-cell lymphoma: evidence for derivation from germinal center B cells? Am J Surg Pathol 2001;25(10):1277-82

16. Copie-Bergman C, Plonquet A, Alonso MA, et al. MAL expression in lymphoid cells: further evidence for MAL as a distinct molecular marker of primary mediastinal large B-cell lymphomas. Mod Pathol 2002; 15(11):1172-80

17. Millan J, Alonso MA. MAL, a novel integral membrane protein of human $\mathrm{T}$ lymphocytes, associates with glycosylphosphatidylinositol-anchored proteins and Src-like tyrosine kinases. Eur J Immunol 1998;28(11):3675-84

18. Rodig SJ, Savage KJ, LaCasce AS, et al. Expression of TRAF1 and nuclear c-Rel distinguishes primary mediastinal large cell lymphoma from other types of diffuse large B-cell lymphoma. Am J Surg Pathol 2007; 31(1):106-12

19. Jaffe ES, Stein H, Campo E, et al. B-cell lymphoma, unclassifiable, with features intermediate between diffuse large B-cell 
lymphoma and classical Hodgkin lymphoma. In: WHO classification of tumours of haematopoietic and lymphoid tissues. Swerdlow SH, Campo E, Harris NL, et al. International Agency for Research on Cancer; Lyon, France; 2008. 267-8

20. Calaminici M, Piper K, Lee AM, Norton AJ. CD23 expression in mediastinal large B-cell lymphomas. Histopathology 2004;45(6):619-24

21. Alizadeh AA, Eisen MB, Davis RE, et al. Distinct types of diffuse large B-cell lymphoma identified by gene expression profiling. Nature 2000;403(6769):503-11

22. Rosenwald A, Wright G, Leroy K, et al. Molecular diagnosis of primary mediastinal B cell lymphoma identifies a clinically favorable subgroup of diffuse large B cell lymphoma related to Hodgkin lymphoma. J Exp Med 2003;198(6):851-62

23. Savage KJ, Monti S, Kutok JL, et al. The molecular signature of mediastinal large B-cell lymphoma differs from that of other diffuse large B-cell lymphomas and shares features with classical Hodgkin lymphoma. Blood 2003;102(12):3871-9

24. Joos S, Küpper M, Ohl S, et al. Genomic Imbalances Including Amplification of the Tyrosine Kinase Gene JAK2 in CD30+ Hodgkin Cells. Cancer Res 2000;60(3): 549-52

25. Joos $S$, Otano-Joos MI, Ziegler $S$, et al. Primary mediastinal (thymic) B-cell lymphoma is characterized by gains of chromosomal material including $9 \mathrm{p}$ and amplification of the REL gene. Blood 1996; 87(4):1571-8

26. Gunawardana J, Chan FC, Telenius A, et al. Recurrent somatic mutations of PTPN1 in primary mediastinal B cell lymphoma and Hodgkin lymphoma. Nat Genet 2014;46(4):329-35

27. Green MR, Monti S, Rodig SJ, et al. Integrative analysis reveals selective 9p24.1 amplification, increased PD-1 ligand expression, and further induction via JAK2 in nodular sclerosing Hodgkin lymphoma and primary mediastinal large B-cell lymphoma. Blood 2010;116(17): 3268-77

- This study reveals an important correlation between genetic alterations 9p24.1 amplification and programmed death ligand 1 expression, being a potential therapeutic target.

28. O'Shea JJ, Holland SM, Staudt LM. JAKs and STATs in immunity, immunodeficiency, and cancer. N Engl J Med 2013;368(2):161-70
29. Steidl C, Gascoyne RD. The molecular pathogenesis of primary mediastinal large B-cell lymphoma. Blood 2011;118(10): 2659-69

30. Steidl C, Shah SP, Woolcock BW, et al. MHC class II transactivator CIITA is a recurrent gene fusion partner in lymphoid cancers. Nature 2011;471(7338): 377-81

-• This study explains all molecular, immunological and pathological mechanisms leading to the phenotype of primary mediastinal large B-cell lymphoma (PMBCL).

31. Hao Y, Chapuy B, Monti S, et al. Selective JAK2 inhibition specifically decreases Hodgkin lymphoma and mediastinal large B-cell lymphoma growth in vitro and in vivo. Clin Cancer Res 2014;20(10):2674-83

-• This research study confirms antitumor activity of the JAK-2 inhibitor in a preclinical setting.

32. Ritz O, Moller P, Ushmorov A. Targeting the intratumor heterogeneity in PMBL. Cell Cycle 2014;13:15

33. Jacobson JO, Aisenberg AC, Lamarre L, et al. Mediastinal large cell lymphoma. An uncommon subset of adult lymphoma curable with combined modality therapy. Cancer 1988;62(9):1893-8

34. Falini B, Venturi S, Martelli M, et al. Mediastinal large B-cell lymphoma: clinical and immunohistological findings in 18 patients treated with different third-generation regimens. Br J Haematol 1995;89(4):780-9

35. Lazzarino M, Orlandi E, Paulli M, et al. Primary mediastinal B-cell lymphoma with sclerosis: an aggressive tumor with distinctive clinical and pathologic features. J Clin Oncol 1993;11(12):2306-13

36. Bishop PC, Wilson WH, Pearson D, et al. CNS involvement in primary mediastinal large B-cell lymphoma. J Clin Oncol 1999; 17(8):2479-85

37. Kirn D, Mauch P, Shaffer K, et al. Large-cell and immunoblastic lymphoma of the mediastinum: prognostic features and treatment outcome in 57 patients. J Clin Oncol 1993;11(7):1336-43

38. Lamarre L, Jacobson JO, Aisenberg AC, Harris NL. Primary large cell lymphoma of the mediastinum. A histologic and immunophenotypic study of 29 cases. Am J Surg Pathol 1989;13(9):730-9

39. Abou-Elella AA, Weisenburger DD, Vose JM, et al. Primary mediastinal large B-cell lymphoma: a clinicopathologic study of 43 patients from the Nebraska Lymphoma Study Group. J Clin Oncol 1999;17(3):784-90

40. Wilson WH, Pittaluga S, Nicolae A, et al. A prospective study of mediastinal gray-zone lymphoma. Blood 2014;124(10):1563-9

41. Elia S, Cecere C, Giampaglia F, Ferrante G. Mediastinoscopy vs. anterior mediastinotomy in the diagnosis of mediastinal lymphoma: a randomized trial. Eur J Cardiothorac Surg 1992;6(7):361-5

42. Hamlin PA, Portlock CS, Straus DJ, et al. Primary mediastinal large B-cell lymphoma: optimal therapy and prognostic factor analysis in 141 consecutive patients treated at memorial Sloan Kettering from 1980 to 1999. Br J Haematol 2005;130(5):691-9

43. Lazzarino M, Orlandi E, Paulli M, et al. Treatment outcome and prognostic factors for primary mediastinal (thymic) B-cell lymphoma: a multicenter study of 106 patients. J Clin Oncol 1997;15(4): $1646-53$

44. Savage KJ, Al-Rajhi N, Voss N, et al. Favorable outcome of primary mediastinal large B-cell lymphoma in a single institution: the British Columbia experience. Ann Oncol 2006;17(1):123-30

45. Todeschini G, Secchi S, Morra E, et al. Primary mediastinal large B-cell lymphoma (PMLBCL): long-term results from a retrospective multicentre Italian experience in 138 patients treated with $\mathrm{CHOP}$ or MACOP-B/VACOP-B. Br J Cancer 2004; 90(2):372-6

46. Zinzani PL, Martelli M, Bertini M, et al. Induction chemotherapy strategies for primary mediastinal large B-cell lymphoma with sclerosis: a retrospective multinational study on 426 previously untreated patients. Haematologica 2002;87(12):1258-64

47. Martelli MP, Martelli M, Pescarmona E, et al. MACOP-B and involved field radiation therapy is an effective therapy for primary mediastinal large B-cell lymphoma with sclerosis. Ann Oncol 1998;9(9):1027-9

48. Zinzani PL, Martelli M, Bendandi M, et al. Primary mediastinal large B-cell lymphoma with sclerosis: a clinical study of 89 patients treated with MACOP-B chemotherapy and radiation therapy. Haematologica 2001; 86(2):187-91

49. Zinzani PL, Martelli M, Magagnoli M, et al. Treatment and clinical management of primary mediastinal large B-cell lymphoma with sclerosis: MACOP-B regimen and mediastinal radiotherapy monitored by (67) Gallium scan in 50 patients. Blood 1999; 94(10):3289-93 
50. Rieger M, Osterborg A, Pettengell R, et al. Primary mediastinal B-cell lymphoma treated with $\mathrm{CHOP}$-like chemotherapy with or without rituximab: results of the Mabthera International Trial Group study. Ann Oncol 2011;22(3):664-70

-• A prospective randomized trial in DLBCL including PMBCL patients with low-risk International Prognostic Index (MiNT). The first study proving the benefit of adding rituximab to $\mathrm{CHOP}$ therapy increasing EFS.

51. Avigdor A, Sirotkin T, Kedmi M, et al. The impact of R-VACOP-B and interim FDG$\mathrm{PET} / \mathrm{CT}$ on outcome in primary mediastinal large B cell lymphoma. Ann Hematol 2014;93(8):1297-304

52. Soumerai JD, Hellmann MD, Feng Y, et al Treatment of primary mediastinal B-cell lymphoma with rituximab, cyclophosphamide, doxorubicin, vincristine and prednisone is associated with a high rate of primary refractory disease. Leuk Lymphoma 2014;55(3):538-43

- This study describes a high rate of primary refractory disease especially in poor-risk PMBCL patients treated with standard R-CHOP.

53. Zinzani PL, Stefoni V, Finolezzi E, et al. Rituximab combined with MACOP-B or VACOP-B and radiation therapy in primary mediastinal large B-cell lymphoma: a retrospective study. Clin Lymphoma Myeloma 2009;9(5):381-5

54. Vassilakopoulos TP, Pangalis GA, Katsigiannis A, et al. Rituximab, cyclophosphamide, doxorubicin, vincristine, and prednisone with or without radiotherapy in primary mediastinal large B-cell lymphoma: the emerging standard of care. Oncologist 2012;17(2):239-49

55. Dunleavy K, Pittaluga S, Maeda LS, et al. Dose-adjusted EPOCH-rituximab therapy in primary mediastinal B-cell lymphoma. $\mathrm{N}$ Engl J Med 2013;368(15):1408-16

-• This study confirms the high activity of an intensified immunochemotherapy regimen inducing a high response and survival rate, notably without consolidation radiotherapy.

56. Mazzarotto R, Boso C, Vianello F, et al. Primary mediastinal large B-cell lymphoma: results of intensive chemotherapy regimens (MACOP-B/VACOP-B) plus involved field radiotherapy on 53 patients. A single institution experience. Int J Radiat Oncol Biol Phys 2007;68(3):823-9

57. De Sanctis V, Finolezzi E, Osti MF, et al. MACOP-B and involved-field radiotherapy is an effective and safe therapy for primary mediastinal large B cell lymphoma. Int J Radiat Oncol Biol Phys 2008;72(4): 1154-60

58. Martelli M, Zucca E, Gospodarowicz M, et al. A randomized multicenter, two arm, phase III comparative study assessing the role of mediastinal radiotherapy after rituximab-containing chemotherapy regimens to patients with newly diagnosed primary mediastinal large B cell lymphoma (PMBCL): The IELSG 37 study. In: Oral presentations. Wiley J, Sons L, Hematological Oncology 2013. 140

59. Mikhaeel NG, Timothy AR, O'Doherty MJ, et al. 18-FDG-PET as a Prognostic Indicator in the Treatment of Aggressive Non-Hodgkin's Lymphoma-Comparison with CT. Leuk Lymphoma 2000;39(5-6): 543-53

60. Spaepen K, Stroobants S, Dupont P, et al. Prognostic value of positron emission tomography (PET) with

fluorine-18 fluorodeoxyglucose ([18F]FDG) after first-line chemotherapy in non-Hodgkin's lymphoma: is [18F]FDGPET a valid alternative to conventional diagnostic methods? J Clin Oncol 2001; 19(2):414-19

61. Zinzani PL, Fanti S, Battista G, et al. Predictive role of positron emission tomography (PET) in the outcome of lymphoma patients. Br J Cancer 2004; 91(5):850-4

62. Cheson BD, Pfistner B, Juweid ME, et al. Revised response criteria for malignant lymphoma. J Clin Oncol 2007;25(5): 579-86

63. Meignan M, Barrington S, Itti E, et al. Report on the 4th International Workshop on Positron Emission Tomography in Lymphoma held in Menton, France, 3-5 October 2012. Leuk Lymphoma 2014; 55(1):31-7

64. Moskowitz C, Hamlin PA Jr, Maragulia J, et al. Sequential dose-dense RCHOP followed by ICE consolidation (MSKCC protocol 01-142) without radiotherapy for patients with primary mediastinal large $B$ cell lymphoma. In: ASH Annual Meeting Abstracts. 2010. 420

65. Savage KJ, Yenson PR, Shenkier T, et al. The outcome of primary mediastinal large B-cell lymphoma (PMBCL) in the R-CHOP treatment era. In: ASH Annual Meeting Abstracts. 2012. 303

- A retrospective study confirming the activity of R-CHOP in PMBCL and encouraging the use of a PET-guided approach to consolidation radiotherapy.

66. Filippi AR, Piva C, Giunta F, et al. Radiation therapy in primary mediastinal B-cell lymphoma with positron emission tomography positivity after rituximab chemotherapy. Int J Radiat Oncol Biol Phys 2013;87(2):311-16

67. Zinzani PL, Broccoli A, Casadei B, et al. The role of rituximab and positron emission tomography in the treatment of primary mediastinal large B-cell lymphoma: experience on 74 patients. Hematol Oncol 2014. [Epub ahead of print]

68. Martelli M, Ceriani L, Zucca E, et al. [18F] fluorodeoxyglucose positron emission tomography predicts survival after chemoimmunotherapy for primary mediastinal large B-cell lymphoma: results of the International Extranodal Lymphoma Study Group IELSG-26 Study. J Clin Oncol 2014;32(17):1769-75

- This study reports the results of a PET-CT scan in a prospective Phase II trial (IELSG 26) in PMBCL patients. It confirms the prognostic value of a negative PET-CT scan and the high rate of PET-CT-positive patients after chemoimmunotherapy. Furthermore, it creates a rationale for a prospective randomized Phase III trial to assess the role of PET-guided radiotherapy.

69. Ceriani L, Zucca E, Zinzani PL, et al. Prognostic value of 18FDG baseline functional PET parameters in primary mediastinal diffuse large B-cell lymphoma. In: Poster presentations. Oncology H, Hematological Oncology 2013. 151-200

70. Han HS, Escalon MP, Hsiao B, et al. High incidence of false-positive PET scans in patients with aggressive non-Hodgkin's lymphoma treated with rituximab-containing regimens. Ann Oncol 2009;20(2):309-18

71. Rodriguez J, Conde E, Gutierrez A, et al Primary mediastinal large cell lymphoma (PMBL): frontline treatment with autologous stem cell transplantation (ASCT). The GEL-TAMO experience. Hematol Oncol 2008;26(3):171-8

72. Kuruvilla J, Pintilie M, Tsang R, et al. Salvage chemotherapy and autologous stem cell transplantation are inferior for relapsed or refractory primary mediastinal large B-cell lymphoma compared with diffuse large B-cell lymphoma. Leuk Lymphoma 2008;49(7):1329-36 


\section{Review Martelli, Di Rocco, Russo, Perrone \& Foà}

73. Sehn LH, Antin JH, Shulman LN, et al. Primary diffuse large B-cell lymphoma of the mediastinum: outcome following high-dose chemotherapy and autologous hematopoietic cell transplantation. Blood 1998;91(2):717-23

74. Gisselbrecht C, Glass B, Mounier N, et al. Salvage regimens with autologous transplantation for relapsed large B-cell lymphoma in the rituximab era. J Clin Oncol 2010;28(27):4184-90
75. Topalian SL, Hodi FS, Brahmer JR, et al. Safety, activity, and immune correlates of anti-PD-1 antibody in cancer. $\mathrm{N}$ Engl J Med 2012;366(26):2443-54

76. Bryan LJ, Gordon LI. Blocking tumor escape in hematologic malignancies: the anti-PD-1 strategy. Blood Rev 2014; Epub ahead of print

77. Study of nivolumab in patients with relapsed or refractory diffuse large B-cell lymphoma (DLBCL) that have either failed or are not eligible for autologous stem cell transplant (CheckMate 139). Available from: http://clinicaltrials.gov/ct2/show/ NCT02038933 